\title{
LOS ÁNGELES DE LA MUERTE: UN RECORRIDO ARTÍSTICO POR LAS GRANDES PANDEMIAS
}

\section{The Angels of Death: An Artistic Journey through the Great Pandemics}

\author{
Javier LIZASOAIN HERNÁNDEZa; Ignacio LIZASOAIN HERNÁNDEZ ${ }^{b}$ \\ ${ }^{a}$ Agregaduría de Educación. Embajada de España (Colombia). 'Departamento de Farmacología y Toxicología. \\ Facultad de Medicina. Universidad Complutense de Madrid (España). \\ Correo electrónico: javier.lizasoain@hotmail.com; Ignacio.lizasoain@med.ucm.es
}

Fecha de recepción: 8 de abril de 2020

Fecha de aceptación: 22 de abril de 2020

Fecha de publicación: 29 de enero de 2021

\begin{abstract}
Resumen
La Historia de la Humanidad se ha visto jalonada por el sufrimiento generado por la presencia permanente de enfermedades. Muchas de estas se convirtieron en auténticas plagas y castigos diezmando la población de ciudades y pueblos. La ciencia avanzaba de manera pausada en la búsqueda de remedios para hacer frente a estas epidemias que eran recibidas con auténtico pavor. Esa misma historia del ser humano asistía de manera simultánea al esfuerzo de ofrecer imágenes de sus efectos. De esta forma, un buen número de pintores, al margen de lenguajes o periodos artísticos, mostraban en tablas y lienzos no sólo la muerte y el dolor sino también el temor, la inseguridad y las huellas emocionales. En este artículo se pretende ofrecer un itinerario de esas formas plásticas que acompañaron a las epidemias desde la Edad Media hasta el presente siglo.
\end{abstract}

Palabras clave: epidemias históricas; arte y enfermedad; imagen de la muerte.

\section{Abstract}

The History of Humanity has been marked by the suffering generated by the permanent presence of diseases. Many of these became real plagues and punishments, decimating the 
population of cities and towns. Science advanced slowly in the search for treatments to deal with these epidemics, which were received with real fear. This same history of the human being simultaneously assisted in the effort to offer images of its effects. In this way, a good number of painters, regardless of language or artistic period, showed in tables and canvases not only death and pain but also fear, insecurity and emotional traces. This article aims to offer an itinerary of these plastic forms that accompanied the epidemics from the Middle Ages to the present century.

Keywords: historical epidemics; art and disease; image of death.

"Detención de las actividades familiares, silencio de la ciudad, soledad en la enfermedad, anonimato en la muerte, abolición de los ritos colectivos de alegría y tristeza: todas estas rupturas brutales en las costumbres cotidianas iban acompañadas de una imposibilidad radical de concebir proyectos de futuro, ya que a partir de entonces la iniciativa pertenecía completamente a la peste".

¿En cuántos periódicos europeos podría aparecer esta crónica? Y, sin embargo, la cita la escribió en 1978, el historiador francés Jean Delumeau (1923-2020). Solo al término de la cita se descontextualiza el escenario de nuestros pueblos y ciudades. El autor sintetizaba de esta forma los efectos que producía la peste en la Europa de los siglos XIV al XVII ${ }^{1}$.

Parece que la Historia - de manera socarrona- no se cansa de ponernos ejemplos de estas "macabras coincidencias". Giovanni Boccaccio (1313-1375) en su Decamerón incluía esta descripción de la ciudad de Florencia durante la peste de 1348: "... cuando a la egregia ciudad de Florencia, noble y famosa cual otra ninguna italiana, llegó aquella cruel y mortífera epidemia (...) habiendo comenzado algunos años antes, en las partes de Oriente (...) prosiguió su crudo $y$ horrible progreso, viniendo de un lugar a otro, y se extendió por el lado de Occidente, sin que valiera contra ella ninguna sesuda precaución ni provisión ninguna de los hombres"

Una vez más la peste, la más temida de las epidemias durante siglos en Europa. Sin duda, la más célebre e impactante fue la que asoló el viejo continente durante la Baja Edad Media y que justifican las palabras de J. Huizinga (18721945): "No hay época que haya impreso a todo el mundo la imagen de la muerte con tan continuada insistencia como el siglo XV"'3.

Así fue. Puede hablarse de un antes y un después en la percepción de la muerte y en su poder fulminante a raíz de esta enfermedad. Además, no fue ella sola la encargada de diezmar la población y de generar un espanto y terror generalizado en la humanidad. Junto a ella, y casi definiendo periodos históricos, fueron apareciendo enfermedades, que parecieron entender la sentencia del clérigo Thomas Malthus (1766-1834) cuando indicaba que la naturaleza se encargaría de buscar el equilibrio roto entre población y recursos por sus desiguales crecimientos ${ }^{4}$ (Fotos 1, 2, 3 y 4).

Estas epidemias y estas enfermedades no solo causaron miles de muertos, sino que en su terrorífico camino cambiaron mentalidades, inocularon temores y transformaron la percepción de conceptos como seguridad y salubridad. Incluso fueron más allá, ese horror y su huella necesitaron una visualización, una exteriorización y la encontraron en el arte y en la literatura (Foto 1).

Se trata, en este artículo, de hacer un recorrido del retrato de las grandes epidemias que hasta hoy han dado muestras de su poder letal (Foto 3). Desde la ya mencionada peste y sus desafortunadas hermanas históricas a las más temidas de nuestra era, hasta la llegada del COVID-19, el SIDA y el Ebola. 


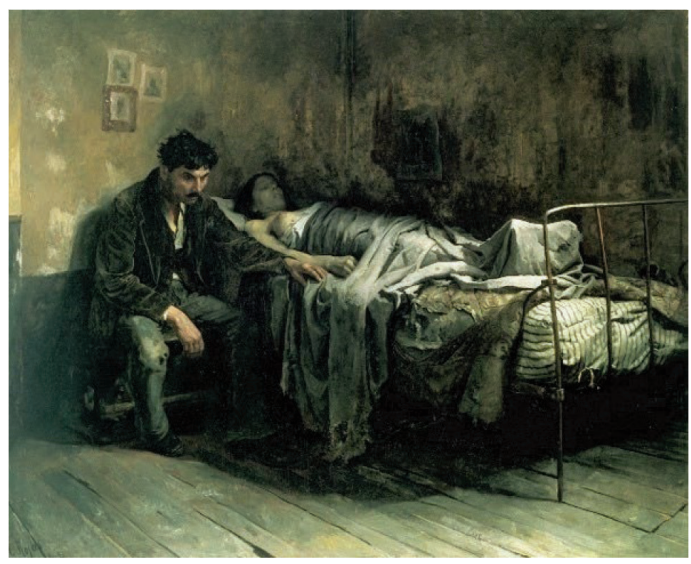

Foto 1. Cristóbal Rojas (1858-1890). La miseria (1886) (Caracas, Galería Arte Nacional).

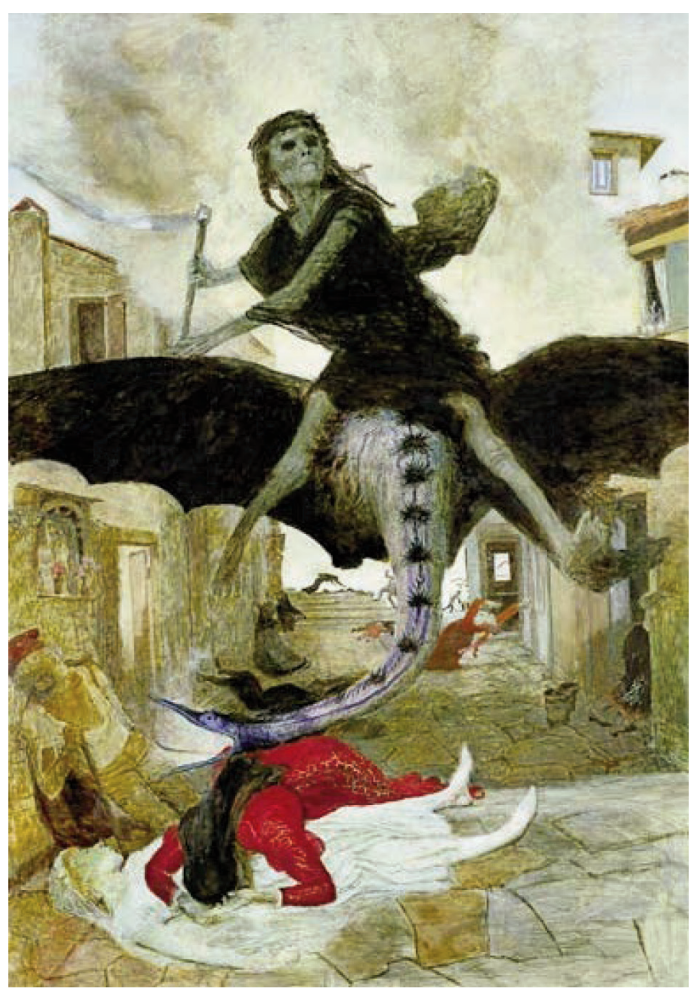

Foto 2. Arnold Böcklin (1827-1901). La plaga (1898). (Basilea, Kunstmuseum).

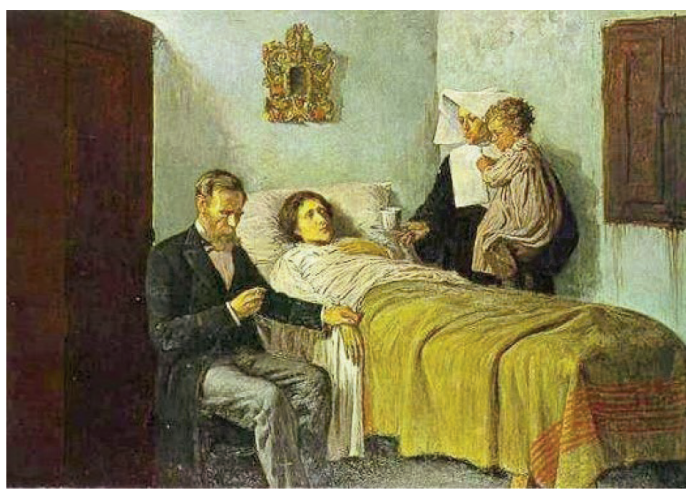

Foto 3. Pablo Picasso (1881-1973). Ciencia y caridad (1897) (Barcelona, Museo Picasso).

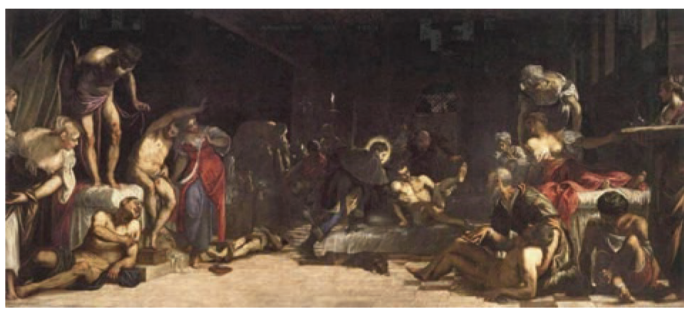

Foto 4. Tintoretto (1518-1594). San Roque en el hospital de leprosos (1549). (Venecia, Iglesia de San Roque).

Ciertamente, como indicaba el historiador neerlandés Huizinga, la Baja Edad Media transformó bruscamente esa percepción ante el efecto devastador de la Peste Negra. De hecho, a partir de ese momento hasta la propia imagen de la Muerte cambió (Foto 2).

Durante el mundo clásico esta no pasaba de ser un personaje secundario, combinándose la presencia de Tánatos, joven alado nada violento, con la de sus hermanas, las Keres, horribles seres femeninos, estas sí agresivas e intimidatorias. Ni Egipto, ni Roma ni el primer cristianismo buscan una imagen de la Muerte, que no de los muertos, ni desagradable ni

Rev. Med. Cine. 2020; 16 (e), 485-502 Ediciones Universidad de Salamanca / @®@@ J. Med. Mov., 2020; 16 (e), 485-502 [ 487 ] 
dramática. Diferente es la imagen creada del Infierno y de los condenados como se pueden ver en los numerosos Juicios Finales que decoran las portadas románicas.

El impacto de la Peste Negra tuvo en el arte un doble efecto. La figura de la Muerte se masculiniza, adopta su forma de esqueleto tradicional, porta una capa oscura y la hoz o guadaña con la que siega la vida. La otra aportación es la Danza de la Muerte. Con ella se subraya la universalidad de la muerte que "no perdona riquezas, linajes, ni títulos de nobleza", igualando a todos y que busca trivializar lo terrorífico, dando una vía de escape al horrorizado europeo que canta y baila junto a su temido visitante.

\section{PESTE NEGRA}

La peste negra o muerte negra se refiere a la pandemia de peste más devastadora en la historia de la humanidad que afectó a Eurasia en el siglo XIV y que alcanzó un punto máximo entre 1347 y 1353. La teoría aceptada sobre el origen de la peste explica que fue un brote causado por una variante de la bacteria Yersinia pestis ${ }^{8}$. Los roedores, como las ratas, portan esta enfermedad, propagándose por medio de sus pulgas. Según Boccaccio ${ }^{2}$ y otros autores, los afectados padecían todos o algunos de los siguientes síntomas: fiebre alta (superando los 40 grados),

\section{EL CINE Y LAS GRANDES EPIDEMIAS}

- Panic in the streets / Pánico en las calles (Elia Kazan, 1950) ${ }^{5^{*}}$

- The Andromeda Strain / La amenaza de Andrómeda (Robert Wise, 1971) 6 $^{*}$

- Rabid / Rabia (Dir. David Cronenberg, 1977)

- Ceguera (Dir. Fernando Meirelles, 2008)

- Contagion / Contagio (Dir. Steven Soderbergh, 2011) ${ }^{7 *}$

*Películas comentadas en la Revista de Medicina y Cine tos, hemoptisis, epistaxis, sed aguda, manchas cutáneas hemorrágicas azules o negras, bubones negros por inflamación de nódulos linfáticos y rotura de estos con supuración maloliente, gangrena en extremidades. También se describen pacientes asintomáticos que morían en 14 horas. La información sobre la mortalidad varía ampliamente entre las fuentes, pero se estima que entre el $30 \%$ y el $60 \%$ de la población de Europa murió desde el comienzo del brote a la mitad del siglo XIV. Aproximadamente 25 millones de muertes tuvieron lugar sólo en Europa junto a otros 40 a 60 millones en África y Asia.

Su origen parece proceder de Asia llegando a Europa a través de los barcos genoveses, diezmando los puertos de Génova, Venecia y Sicilia y desde ellos al conjunto de ciudades europeas.

Ante el primer brote se determinaba el aislamiento, el cierre de las rutas comerciales, el control en las puertas de las ciudades para impedir la entrada de foráneos, asegurar el abastecimiento de la ciudad, y, por supuesto, convocar actos religiosos.

Las primeras ilustraciones proceden de miniaturas y códices medievales en las que se nos muestran los causantes de la Peste. Si por un lado vemos el ataque que recibe un ciudadano por parte de numerosas ratas ante la mirada aterrorizada de los testigos (por entonces se pensaba que era la mordedura de la rata y no la picadura de la pulga) en la miniatura de "Le Miroir Historial" (Foto 5).

Al mismo tiempo podemos ver a Cristo enviando las flechas de la peste sobre unos cuerpos ya moribundos en la miniatura de Hannover (Foto 12). En otras ocasiones, es la propia muerte la que envía esas flechas.

En otras miniaturas, aparecen los apestados asistidos fuera de las ciudades en hospicios por parte de religiosos mostrando los característicos bubones bien visibles en todo el cuerpo.

Esta cierta inocencia o simplicidad medieval choca con las visiones trágicas posteriores. 


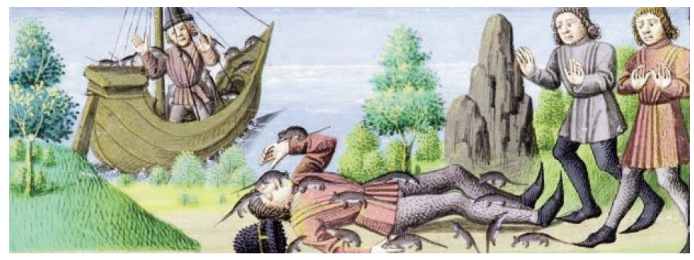

Foto 5. Anónimo (siglo XV). Hombre devorado por las ratas. Le Miroir Historial. (Chantilly, Museo Condè).

Si bien no ilustra directamente los efectos de la peste, el célebre Triunfo de la muerte de Brueghel si muestra esa imaginería tardomedieval en torno a la Muerte (Foto 6). Esta aparece con la guadaña sobre un famélico corcel rojo dirigiendo a su ejército de esqueletos para que dirijan a los derrotados ejércitos de vivos a los ataúdes. En medio aparecen alegorías sobre la codicia y avaricia (barriles con oro), sobre la gula, lujuria y pereza (jugadores y amantes), también retratos de reyes, cardenales y obispos que caen en las garras de la muerte igualándose a los campesinos y plebeyos. El pintor, conocedor de la pintura flamenca de Van de Weyden y de Van Eyck, pero de manera especial influido por las imágenes de El Bosco, incluye torturas, suicidios

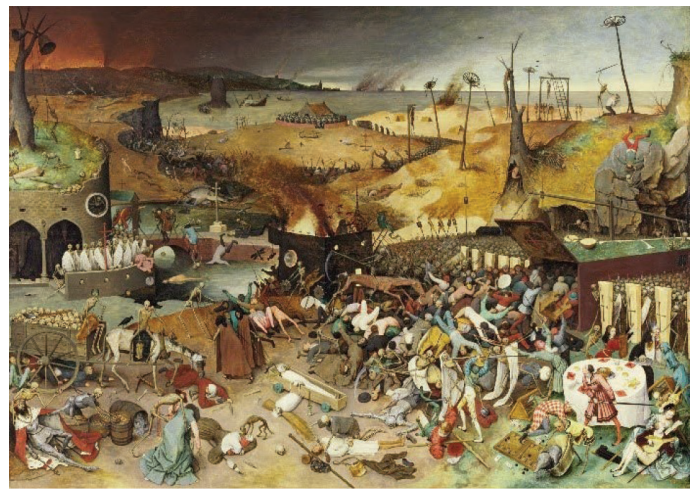

Foto 6. Pieter Brueghel El Viejo (1525-1569). El triunfo de la muerte (1562). (Madrid, Museo del Prado). y ejecuciones en un paisaje que presupone por el detallismo pudo ver en directo.

El caos también domina la Plaza del mercado napolitano de Gargiulo (Foto 7) durante la peste de 1656 ante la atenta mirada de Cristo en los cielos. Los cuerpos se hacinan y ocupan todo el espacio, los pocos vivos se afanan en cargarlos en carros y meterlos en ataúdes bajo las directrices de personajes montados a caballo. La vida parece concentrarse en el centro de la escena donde frente a la dominante palidez de los fallecidos aparecen manchas de color $y$, muy especialmente, introduce la esperanza de la nueva vida en el grupo formado por la madre, muerta ya, $y$ su pequeño que busca en el pecho materno el alimento que le garantice seguir viviendo.

Poussin en La peste de Azoth (Foto 8) recurre a estrategias similares al mostrar el contraste cromático entre vivos y muertos e incluir en el centro a la misma madre rodeada de un bebé muerto y otro que se aferra a la vida a punto de ser rescatado por el miguelangelesco hombre que se tapa nariz y boca. Como representante del Clasicismo la escena se adecúa perfectamente a los frisos romanos horizontales. A la izquierda puede verse la fachada del templo de Dagón y en su pórtico la

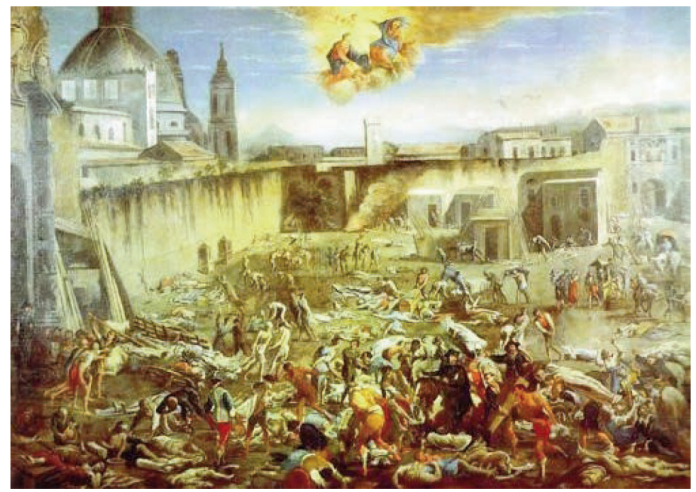

Foto 7. Domenico Gargiulo (1612-1679). La plaza del mercado de Nápoles durante la peste de 1656 (1657). (Nápoles, Museo San Martino). 


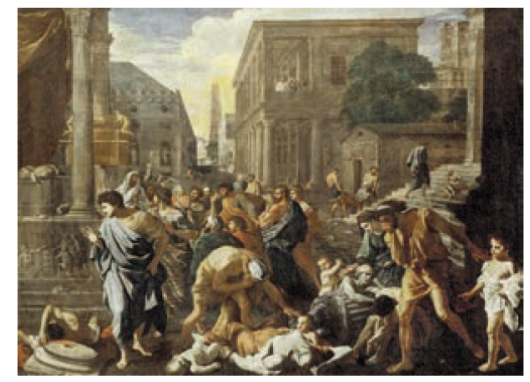

Foto 8. Claude Poussin (1594-1665). La peste de Azoth (1630-31). (París, Museo del Louvre).

robada Arca de la Alianza, motivo por el cual Yahvé ha castigado a los filisteos con la peste. La contención de los gestos de las figuras, los contornos claramente definidos, figuras como los dos hombres que trasladan a un moribundo a la derecha que evocan a su admirado Rafael y las construcciones subrayan ese apego al mundo clásico que definió el estilo de Poussin.

Gros en Los apestados de Jaffa (Foto 9) muestra el orientalismo tan propio del Romanticismo al igual que la preferencia por personajes derrotados y desahuciados como los recluidos en este patio. En medio aparece Bonaparte estirando el brazo en un gesto que bien puede recordar a Cristo en las curaciones de ciegos o leprosos. Por su parte, Goya aleja esos contornos

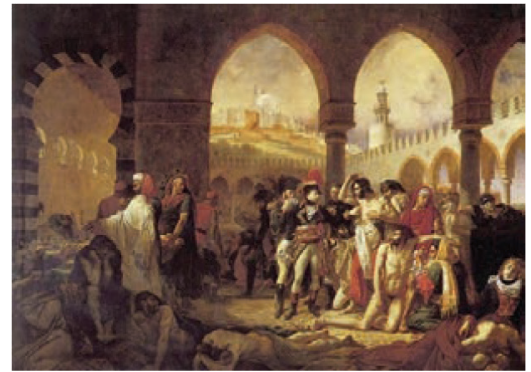

Foto 9. Antoine-Jean Gros (1771-1835). Los apestados de Jaffa (1804). (París. Museo del Louvre).

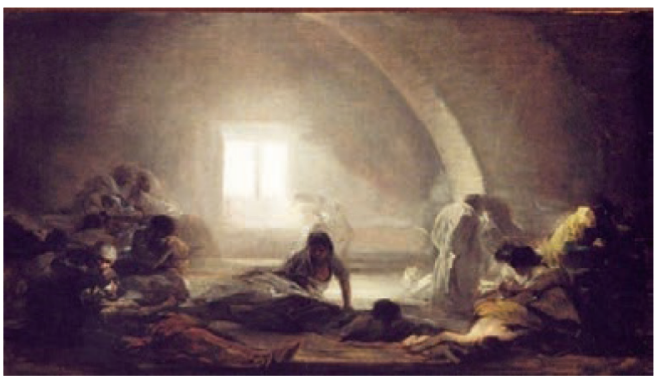

Foto 10. Francisco de Goya (1746-1828). Hospital de apestados (1808-10) (Madrid, Colección Marqués de la Romana).

de Poussin en la magnífica imagen de los apestados también apartados o recluidos (Foto 10).

Como castigo divino, la población recurría a la mediación de santos para lograr mitigar los efectos de estas epidemias. Cada enfermedad tenía su santo protector. En el caso de la peste, dos son los más frecuentes. San Roque sería el más reproducido, siendo fácilmente identificado por la presencia del perro que, según la leyenda, le llevaba a diario el pan en su refugio

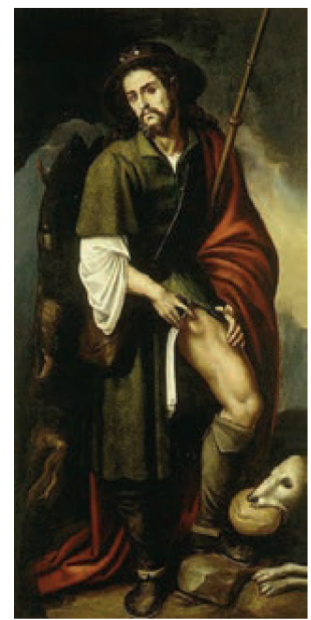

Foto 11. Francisco Ribalta (1565-1628). San Roque. (1625). (Valencia, Museo Bellas Artes). 
y la inclusión del bubón inguinal. Así lo representa Francisco Ribalta en el cuadro conservado en el Museo de Bellas Artes de Valencia (Foto 11).

Un segundo santo asociado a la peste es San Sebastián. Este centurión romano fue inicialmente martirizado atándole a un árbol y lanzándole todas las flechas que pudieran caber en su cuerpo. Precisamente su vinculación con las flechas a las que sobrevivió le hicieron merecedor de ser invocado por los cristianos para protegerle de una epidemia que como vimos procedía de las flechas mandadas por Cristo (Foto 12).

Lieferinxe le muestra en sagrada conversación con Dios con todo el cuerpo cubierto de

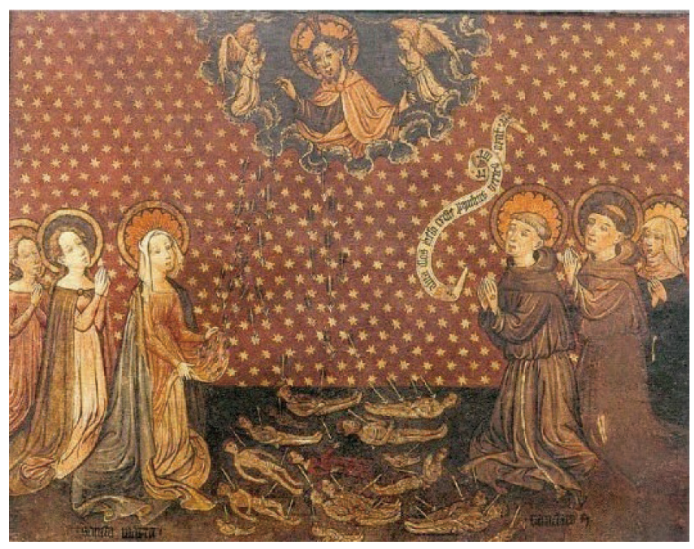

Foto 12. Anónimo. Cristo enviando sobre la tierra las flechas de la peste (1424). (Hannover, Niedersächsisches Landesmuseum).

\section{EL CINE Y LA PESTE}

- Nosferatu (F. F. Mornau, 1922)

- The Seventh Seal / El Séptimo sello (Ingmar Bergman, 1957)

- La Armada Brancaleone (Mario Monicelli, 1966)

- La peste (Luis Puenzo, 1992) 9* $^{*}$

*Películas comentadas en la Revista de Medicina y Cine

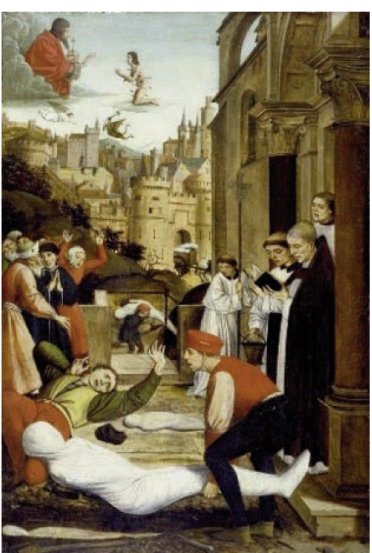

Foto 13. Josee Lieferinxe (XV-XVI). San Sebastián intercede en una epidemia de peste (1499).

(Baltimore, Walters Art Gallery).

flechas y en la parte inferior auxiliando a la población ya castigada por la peste (Foto 13).

LEPRA

La lepra o enfermedad de Hansen es una enfermedad infecciosa crónica producida por el bacilo Mycobacterium leprae que provoca úlceras cutáneas, daño neurológico, mucosa de vías respiratorias altas, afectación ocular y debilidad muscular que empeora con el tiempo ${ }^{10} . M$. leprae se multiplica muy despacio y el periodo promedio de incubación de la enfermedad es de 5 años. En algunos casos los síntomas pueden aparecer en 1 año, pero también pueden tardar hasta 20 años. Los expertos piensan que la bacteria se disemina cuando una persona inhala las pequeñas gotas en el aire liberadas cuando alguien con lepra tose o estornuda. La bacteria también se puede transmitir por contacto con los líquidos nasales de una persona con lepra. Tiene dos formas comunes: la tuberculoide y la lepromatosa. Ambas formas ocasionan úlceras en la piel. Sin embargo, la forma lepromatosa es más grave. Esta produce grandes protuberancias e hinchazones (nódulos). Sus complicaciones más severas son la desfiguración, la deformidad 
y la discapacidad (ya sea por el compromiso neurológico o la ceguera). La lepra fue históricamente incurable, mutilante y vergonzosa.

El hecho de que la curación de un leproso sea uno de los milagros recogidos en los Evangelios hace que su presencia en el arte sea temprana. Al leproso se le permitía mendigar en la ciudad para conseguir su sustento, siempre que cumpliese dos condiciones: ir anunciándose con una campanilla y que viviera extramuros. Esta segunda condición se puede ver ya en sendas representaciones del siglo XII: el mosaico de la catedral de Monreale (Foto 14) y el fresco procedente de Tahull (Foto 15). En ambas el personaje aparece al otro lado de la puerta de la ciudad y muestra las lesiones cutáneas.

El mismo tema, pasados los siglos, recibirá un tratamiento muy diferente por parte de dos tradiciones pictóricas. Por un lado, la italiana, representada por Cosimo Rosselli (1439-1507) quien en la escena del Sermón de la Montaña de la Capilla Sixtina (Foto 16) incluye en la esquina derecha la curación del leproso. La escena pasa desapercibida no sólo por su ubicación y la multitud que puebla el cuadro sino por la suavidad en el tratamiento de la enfermedad.

Muy diferente la segunda tradición, la germánica o centroeuropea que extrema la crudeza de la enfermedad. Tanto en La Capa de San Martín y el mendigo leproso (Foto 17) como

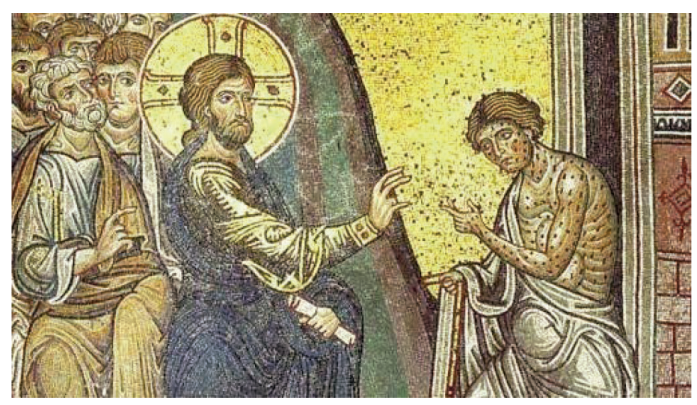

Foto 14. Anónimo. Mosaico de la curación del leproso (siglo XII). (Catedral de Monreale).

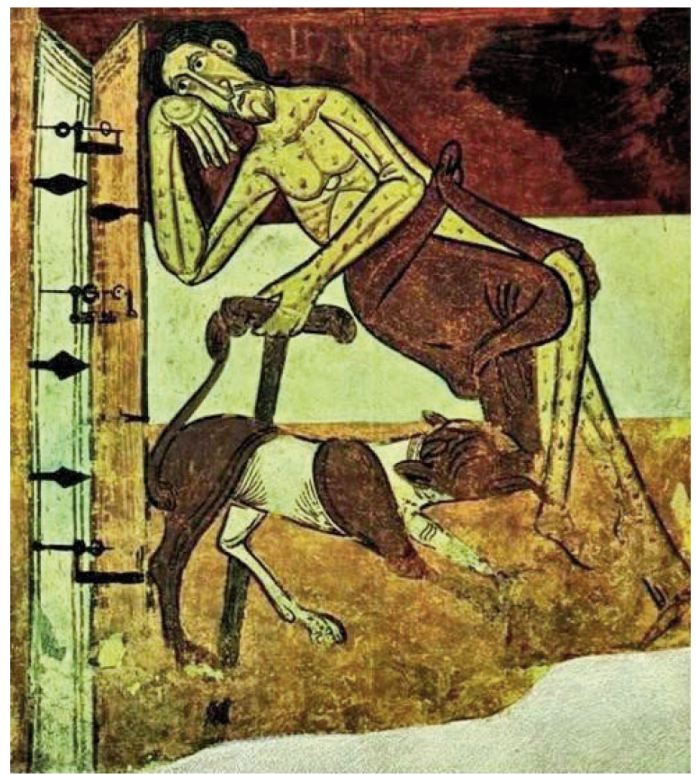

Foto 15. Anónimo. Leproso de Tahull (siglo XII). (Barcelona, MNAC).

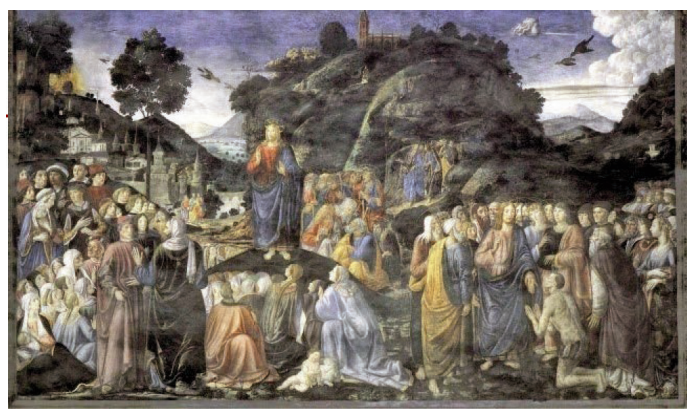

Foto 16. Cosimo Rosselli (1439-1507). Sermón de la Montaña y curación del leproso (1481-82). (Vaticano, Capilla Sixtina).

en la tabla derecha del tríptico del Juicio Final de Bernaert Van Orley (Foto 18) es evidente el interés de ambos maestros. En el primer caso, mientras que el legionario romano corta su capa para entregársela al leproso, este mendiga su limosna mostrando su cuerpo lleno de lesiones y 

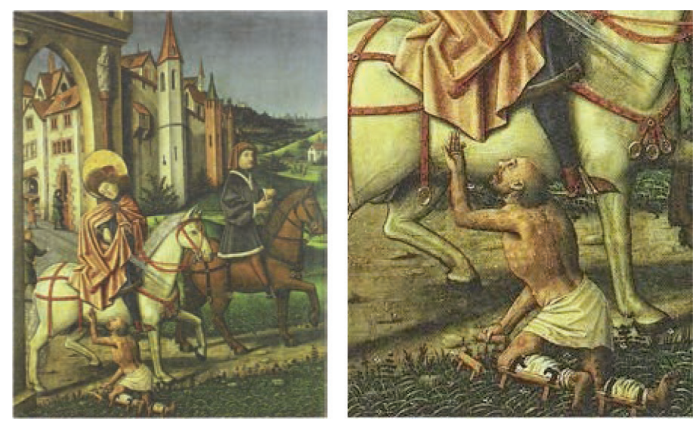

Foto 17. Círculo de Konrad Wintz. La capa de San Martín y el mendigo leproso (1450).

(Basilea, Museo de Arte).

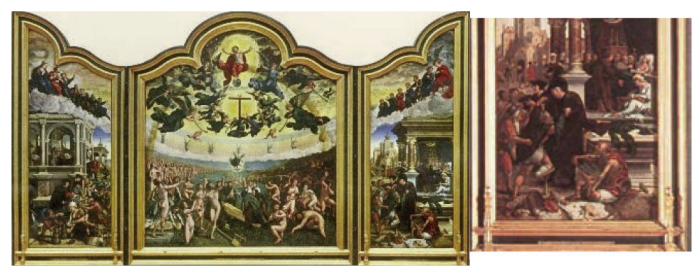

Foto 18. Bernaert Van Orley (1487/91-1541). Tríptico Juicio Final (1517-24). (Amberes, Museo Real de Bellas Artes).

sus extremidades inferiores atadas a tablillas de madera que le permiten moverse.

Los leprosos situados en las escaleras de la tabla derecha, en el Tríptico, muestran todo el repertorio de signos externos: facies eonina piernas en ángulo recto, granul I ste, también la lepra tendel citado San Martín a I empre en el instante des I, nariz silla de montar, oma en el labio superior...

Como en el caso de a pe drá su santo protector. Se trata quien se e suele representar si crito junto al mendigo.

Si bien no fue demasiado frecuente en el arte, también San Francisco es invocado por los fieles para propiciar la curación. El pintor Zacarías González Velázquez lo representa (Foto 19)

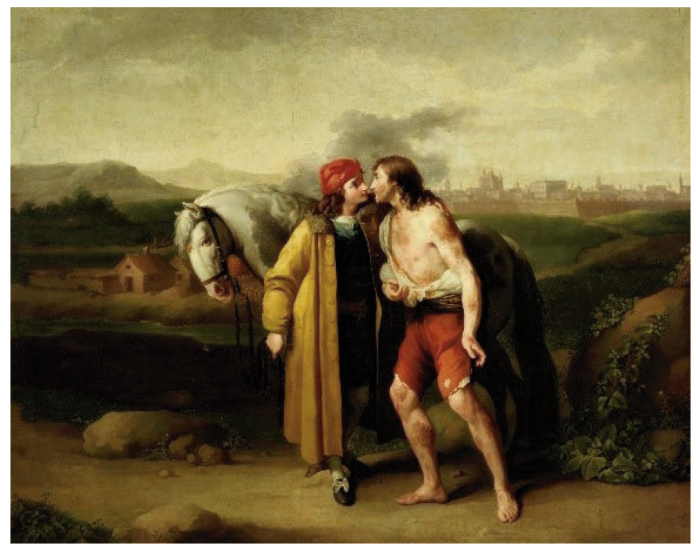

Foto 19. Zacarías González Velázquez (17631834). San Francisco abrazando un leproso (1787) (Madrid, Museo del Prado).

\begin{tabular}{l}
\multicolumn{1}{c}{ EL CINE Y LA LEPRA } \\
- Ben Hur (William Wyler, 1959) \\
- Molokai, la isla maldita (Luis García, 1959) \\
- Life of Brian / La vida de Brian (Terry Jones, \\
1979) \\
- City of Join / La ciudad de la alegría (Roland \\
- Joffé, 1992) \\
- Kingdom of Heaven / El reino de los cielos \\
(Ridley Scott, 2005)
\end{tabular}

en el momento en el que aún siendo un joven rico se acerca a un leproso para abrazarle. Vuelve la carencia de dramatismo y la suavidad en la presencia de las lesiones que no oculta el enfermo.

\section{SíFILIS}

La sífilis es una enfermedad infecciosa de curso crónico, transmitida principalmente por contacto sexual, producida por la espiroqueta Treponema pallidum. Los síntomas en los adultos se dividen en sífilis primaria (pequeña llaga, llamada chancro, en el lugar de la infección), secundaria (erupción que comienza en el tronco, 
pero que eventualmente cubre todo el cuerpo, incluso las palmas de las manos y las plantas de los pies), latente (sin tratamiento, la enfermedad pasa a la etapa oculta que es asintomática y puede durar años) y terciaria ( $15 \%$ al $30 \%$ de las personas infectadas que no reciben tratamiento tendrán complicaciones que puede afectar a nivel ocular, cardiovascular, hepático, osteoarticular y producir neurosífilis) ${ }^{11}$. La enfermedad barrió Europa a partir de 1495, con tasas de morbilidad y mortalidad elevadísimas.

Tal vez sea la enfermedad que más ha servido para transmitir sentimientos xenófobos dado que en cada país recibía el nombre del enemigo ancestral. Fue conocida como "mal francés", "mal español", "mal napolitano", "polaco", "alemán"... Como enfermedad de transmisión sexual siempre fue asociada a largos asedios o campañas militares, así como al paulatino crecimiento de las grandes urbes europeas.

Su origen asociado a una promiscuidad y a una vida un tanto licenciosa hizo que padecerla fuera motivo de vergüenza social. Tal vez por eso fue protagonista de la serie de seis cuadros pintados por William Hogarth (1697-1764), Matrimonio a la moda, quien en la línea de Goya

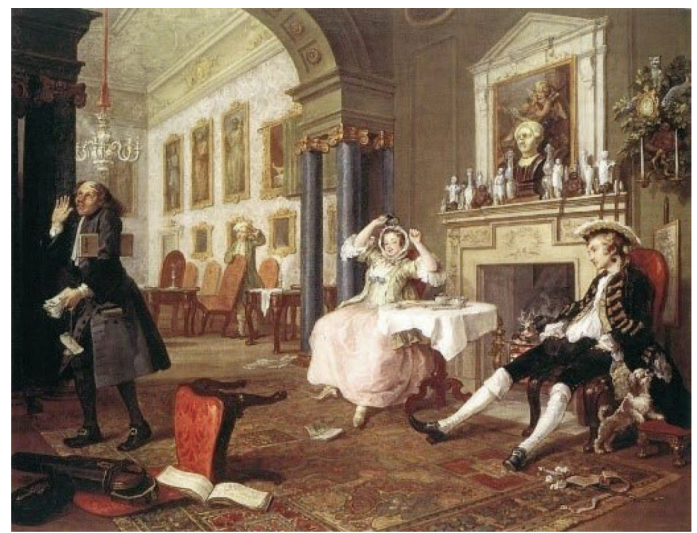

Foto 20. William Hogarth (1697-1764). Casamiento a la moda II (Tete a tete) (1743). (Londres, National Gallery). con sus Caprichos se encargó de criticar ferozmente ciertos convencionalismos sociales. En el segundo episodio de esta serie, el titulado Tete a Tete (Foto 20) podemos ver el interior de un salón nobiliario de estilo palladiano, muy de moda en el Reino Unido en el siglo XVIII.

La teatral escena esconde guiños a una vida que ha conducido al vizconde a padecer la sífilis como puede apreciarse en la mancha oscura que no esconde el pintor en el cuello. Entre estos detalles podemos ver en la chimenea la presencia de un busto sin nariz (símbolo de la impotencia), un cuadro de Cupido que toca el violín con un arco sin cuerdas y en el salón anexo, en medio de cuadros religiosos, una pintura parcialmente cubierta que, sin embargo, muestra un pie desnudo tumbado en un lecho.

Los personajes acentúan con su actitud un desinterés recíproco. El vizconde, recostado, deja que un perro huela un pañuelo femenino en su bolsillo perteneciente a otra mujer e ignora la daga envainada, pero con la punta rota, también símbolo de

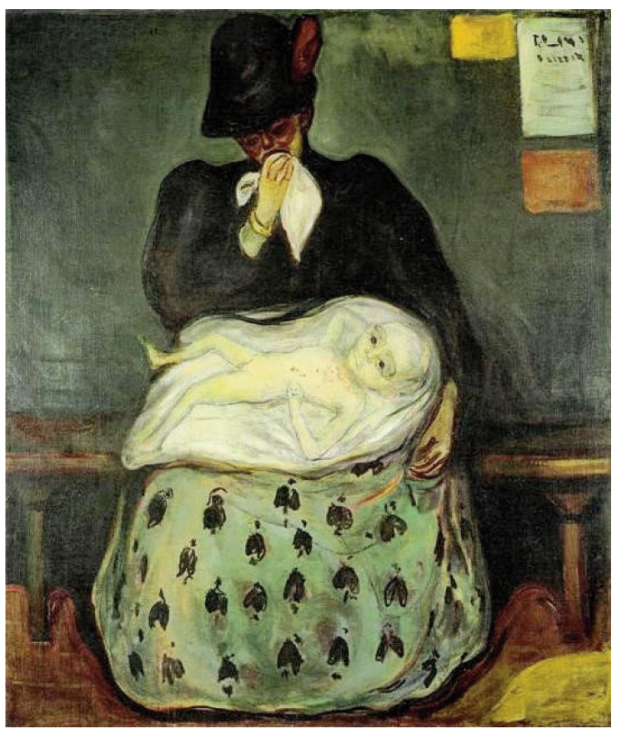

Foto 21. Edvard Munch (1863-1944). Herencia (1897-9). (Oslo, Museo Munch). 
impotencia. El rostro de la mujer revela una noche placentera con alguien que debió salir corriendo (silla derribada) pero con quien parece tener comunicación a través del espejo de la mano. Finalmente, el gesto del contable manifiesta su resignación ante un patrimonio derrochado.

Menos escenográfica es la imagen que ofrece Munch (1863-1944) de la enfermedad en su cuadro titulado Herencia (Foto 21). Aparece una madre llorando en la consulta de un médico mientras observa a su pequeño a quien le ha transmitido la enfermedad. El pintor noruego tuvo, durante toda su vida, auténtico pavor a las enfermedades lo que se tradujo en su firme voluntad de no tener hijos para no transmitirles sus genes. La sífilis congénita no fue sistematizada hasta finales del siglo XIX y presentaba varios efectos que pueden verse en el retrato del pequeño tales como deformidades en los huesos, piel arrugada, nariz hundida o de silla de montar, prominencia frontal, rágades peribucales y bajo peso. El cuadro recibió una crítica muy severa

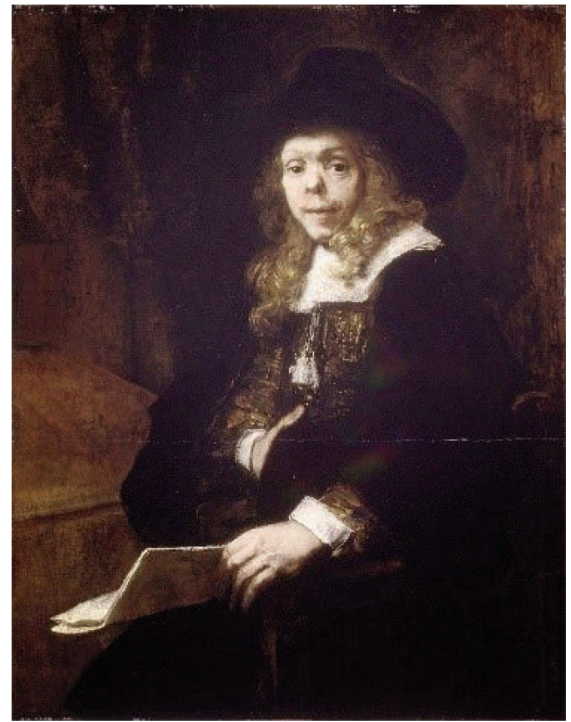

Foto 22. Rembrandt (1606-1669). Retrato de Gerard de Lairesse (1665-7). (Nueva York, Museo Metropolitano). en su época, aunque el propio pintor aseguraba que "mi niño sifilítico, colgado en mi propia sala, obtuvo el mayor éxito de hilaridad".

Estas manifestaciones externas aparecen también en el retrato que Rembrandt (16061669) hizo de su amigo Gerard de Lairesse (Foto 22). Los cronistas del momento subrayaban la fealdad de este pintor, dibujante y crítico de arte. Como quiera que estas manifestaciones no se asociaban con la sífilis congénita que padecía el retratado, Rembrandt no quiso perpetuar a su amigo asociándolo con esta enfermedad, sino que procuró retratarlo tal y como era, suavizando mediante unos rasgos difuminados los rasgos que le caracterizaban. Años más tarde,

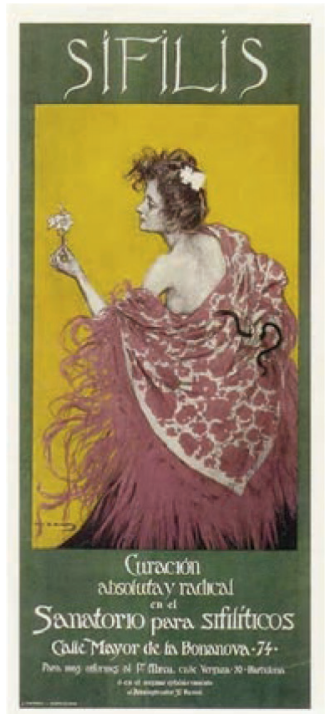

Foto 23. Ramón Casas (1866-1932). Sífilis (1900)

(Barcelona, MNAC).

\section{EL CINE Y LA SÍFILIS}

- Vergüenza (Juan Pérez Berrocal, 1928)

- Shizukanaru Ketto / Duelo silencioso (Akira Kurosawa, 1949)

- Out of Africa / Memorias de África (Sydney Pollack, 1985) 
el retratado quedaría ciego, para algunos como consecuencia de esta enfermedad.

Ramón Casas (1866-1932) en plena industrialización de Barcelona ofrece la última imagen de esta enfermedad que incluimos. Su cartel, Sífilis (Foto 23), elegante y suave a primera vista, muestra una joven que ofrece una flor a quien quiera cogerla, y a la mortífera serpiente en la mano que esconde en la espalda.

\section{TUBERCULOSIS}

La tuberculosis, llamada históricamente tisis, es una infección bacteriana contagiosa que afecta principalmente a los pulmones, pero puede propagarse a otros órganos. La especie de bacteria más importante y representativa causante de la tuberculosis es Mycobacterium tuberculosis o bacilo de Koch, aunque otras micobacterias lo pueden producir. La tuberculosis se contagia por vía aérea. Es, posiblemente, la enfermedad infecciosa más prevalente del mundo. Considerando su forma latente, en la cual no presenta síntomas, se estima que afecta al $33 \%$ de la población mundial. Asimismo, es la segunda causa de muerte a nivel global, y la primera entre las enfermedades infecciosas. Los síntomas clásicos de la tuberculosis son: tos crónica con hemoptisis, fiebre, sudores nocturnos y pérdida de peso. La infección de otros órganos causa una amplia variedad de síntomas ${ }^{12,13}$.

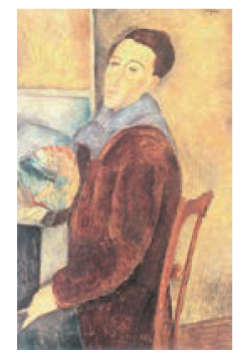

Foto 24. Amadeo Modigliani (1884-1920). Autorretrato (1919). (Sao Paolo, Museo Arte Contemporáneo).
Durante años fue considerada la "enfermedad romántica" por el cuadro de manifestaciones que ofrecía en el enfermo. Modigliani (18841920) un año antes de su muerte nos dejó este Autorretrato (Foto 24) en el que podemos apreciar algunos de estos síntomas: mirada melancólica, perdida y triste, palidez y delgadez y facies héctica. Padeció la enfermedad desde adolescente, agravada por el alcohol, muriendo finalmente por una meningitis tuberculosa.

Estos mismos rasgos los podemos encontrar en uno de los grandes iconos de la pintura occidental, Nacimiento de Venus (Foto 25) de Sandro Botticelli (1445-1510). Simonetta Vespucci, musa del pintor, aparecía en este cuadro como prototipo de la nueva belleza renacentista. Su mirada nostálgica, las formas onduladas y la palidez de su piel desnuda definieron ese nuevo canon "creado" por Botticelli que, sin embargo, eran

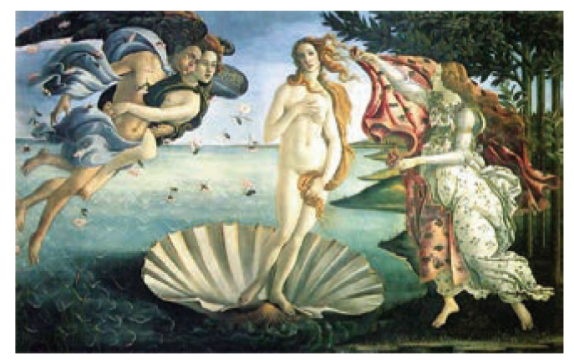

Foto 25. Sandro Botticelli (1445.1510). Nacimiento de Venus (1485-86). (Florencia, Galería Uffizi).

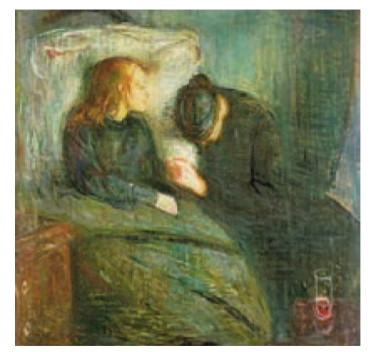

Foto 26. Edvard Munch (1863-1944). La niña enferma (1885-56). (Oslo, Museo Nacional). 
reflejo de una enfermedad, la tuberculosis, que seis meses después se la llevaba.

La imagen que ofrece Munch en La niña enferma (Foto 26) se aleja mucho de esa dulzura y esa armonía de las formas. Si tenemos en cuenta el siguiente testimonio del pintor es justificable la desolación y la amargura que transmite este cuadro en el que aparecen su hermana Sophie y su tía Karen: "... mi abuela materna murió de tuberculosis. Mi madre murió de tuberculosis, al igual que su hermana Hansine. Al parecer la tía que vino (a vivir) con nosotros también tenía tuberculosis. Toda su vida sufrió catarros con expectoraciones de sangre. Mi hermana Sophie murió de tuberculosis. Llegué enfermo al mundo. Apenas pude asistir al colegio. Tenía hemorragias y expectoraciones de sangre. Mi hermano tenía los pulmones delicados y murió de pulmonía. Mi abuelo paterno, el deán, murió de tuberculosis de médula. De allí creo que le vino a mi padre ese nerviosismo y esa vehemencia enfermizos; los mismos males que fuimos desarrollando crecientemente los hijos".

La tía llora desconsoladamente mirando al suelo mientras agarra la mano de su sobrina quien apoyada en la almohada parece con su mirada generar una pequeña esperanza en Karen.

Más desesperanzadora, es La primera y última comunión (Foto 27) de Cristóbal Rojas (1858-1890) quien con tan solo 32 años moriría también de tuberculosis. La soledad y aceptación del destino escrito en la niña caquéctica que asiste a su primera comunión y probablemente última dominan ese reducido espacio. Este mismo ambiente aparece en La miseria (1886) del mismo autor (Foto 1).

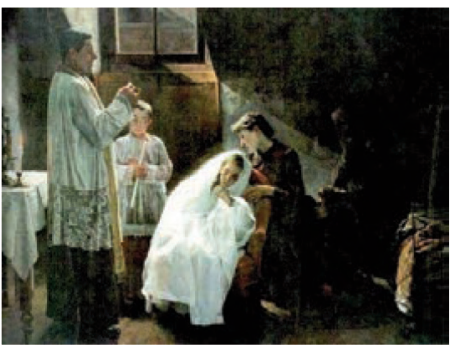

Foto 27. Cristóbal Rojas (1858-1890). La Primera y la última communion (1888). (Caracas, Galería de Arte Nacional).

\section{EL CINE Y LA TUBERCULOSIS}

- Camille o La dama de las Camelias (George Cukor, 1936)

- Midnight Cowboy / Cowboy de medianoche (John Schlesinger, 1969)

- Amargo despertar (Vittorio De Sica, 1973)

- Edvard Munch (Peter Watkins, 1974)

\section{VIRUELA}

La viruela fue una enfermedad infecciosa grave, contagiosa, causada por el virus Variola virus que, en algunos casos, podía ser letal. Se considera erradicada desde 1980. Junto a la peste bovina, son las dos únicas enfermedades que han sido erradicadas de la naturaleza por el ser humano. Según la forma clínica de presentación de la viruela, se clasificaba en: i) viruela mayor (común, modificada, lisa y hemorrágica). Históricamente, la viruela mayor tuvo una tasa de mortalidad de aproximadamente el $30 \%$; sin embargo, la viruela lisa y la hemorrágica solían ser siempre mortales. ii) viruela menor, es un tipo menos común de la viruela y una enfermedad mucho menos grave, cuyas tasas de mortalidad fueron históricamente del $1 \%$ o menores. Los primeros síntomas eran fiebre, malestar, dolor de cabeza y en el cuerpo y, algunas veces, vómitos. La erupción se manifestaba primero en la lengua 
y en la boca en forma de máculas y pápulas que después se convertían en llagas y se extendían por todo el cuerpo, formándose vesículas, pústulas y costras. Se contagiaba de una persona a otra por contacto directo y prolongado. También podía transmitirse por medio del contacto directo con fluidos corporales infectados o con objetos contaminados. Los seres humanos eran los únicos portadores naturales del virus de la viruela. No se conocen casos de viruela transmitidos por insectos o animales ${ }^{14}$.

Denominada durante años "el ángel de la muerte" fue una de las plagas más temidas, no sólo por su letalidad sino por las terribles huellas que dejaba especialmente en el rostro.

No es muy frecuente encontrarse con un retrato como el que el pintor flamenco Joost Susterman (1597-1681) dejó de Fernando I/ de Médici (Foto 28). En él puede verse al que después fuera gobernante de Toscana totalmente

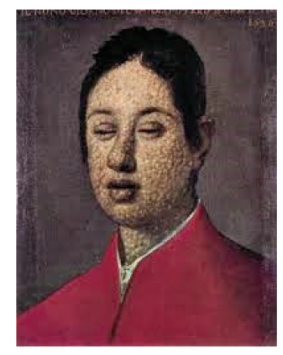

Foto 28. Joost Susterman (1597-1681) Fernando Il de Médici (1626). (Florencia, Palazzo Pitti).

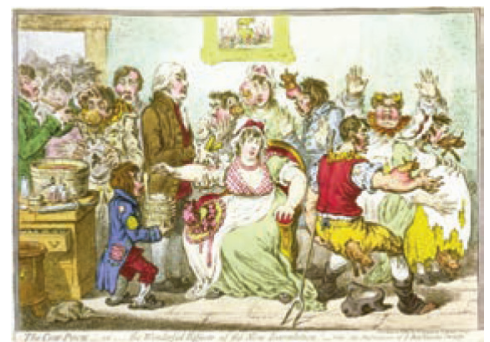

Foto 29. James Gillray (1757-1815). The CowPock (1802). (Washington, Library of Congress).

\section{EL CINE Y LA VIRUELA}

- The King's Whore / La puta del rey (Axel Cortí, 1992) ${ }^{15}$

- A Royal Affair / Un asunto real (Nikolaj Arcel, 2012) ${ }^{16}$

- 22 ángeles (Miguel Bardem, 2020)

* Películas comentadas en la Revista de Medicina y Cine

cubierto su rostro de las vesículas características de la viruela en una extensión tal que le afecta a los párpados lo que explicaría los ojos cerrados y a los propios labios que deja abiertos ante la dificultad de respirar. Cuesta conocer las razones de un retrato tan naturalista entre nobles a los que se les solía suavizar sus "imperfecciones". Podría tratarse de un retrato moralizante para demostrar el valor de la fortaleza de ánimo para superar un castigo de la naturaleza.

Es una enfermedad que cuenta con una representación gráfica abundante de todo el proceso de vacunación de Jenner. La caricatura The Cow-Pock (Foto 29), de James Gillray (1757-1815) refleja la incredulidad y la superstición ante el avance de la ciencia. Dado que la vacuna procedía de la muestra de una póstula de una ordeñadora con el virus de la viruela bovina se temía que al vacunado le salieran cuernos u otras partes de la vaca.

\section{SIDA}

El síndrome de inmunodeficiencia adquirida (SIDA) es un espectro de enfermedades provocadas por la infección causada por el virus de la inmunodeficiencia humana (VIH). Tras la infección inicial, una persona puede estar asintomático o padecer un cuadro tipo influenza (cuadro pseudogripal). Habitualmente, le sigue un periodo prolongado sin síntomas. A medida que la infección progresa, interfiere con el sistema inmunitario, aumentando el riesgo de infecciones comunes como la tuberculosis, además de otras infecciones oportunistas y tumores que raramente afectan a las personas 
con un sistema inmunitario competente. El VIH se contagia principalmente por vía sexual, transfusiones de sangre contaminada, agujas hipodérmicas y de la madre al niño durante el embarazo y/o parto. Entre su descubrimiento (1981) y el 2014, el SIDA ha causado cerca de 40 millones de muertes en todo el mundo, principalmente en África donde la disponibilidad del tratamiento antiretroviral no está disponible ${ }^{17,18}$.

Con su aparición en la década de los ochenta del pasado siglo regresaron los "castigos divinos". El dolor y el drama de esta enfermedad se vieron acompañados por unas descalificaciones morales hacia quienes la padecían.

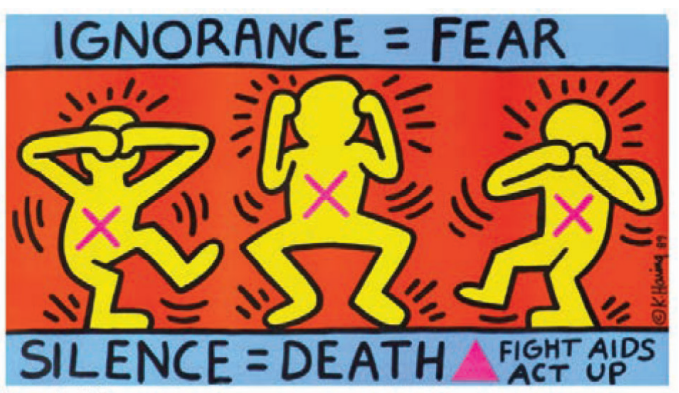

Foto 30. Keith Haring (1958-1990). Ignorance=Fear (1989). (París, Col. Noirmontarproduc).

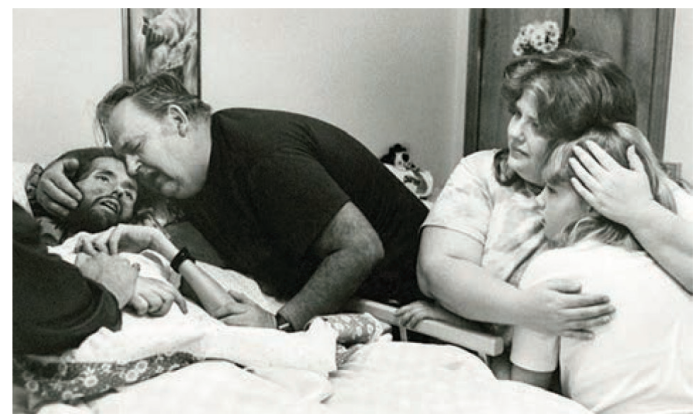

Sin duda, fue la primera enfermedad de un mundo globalizado y televisado. Su evolución fue transmitida minuto a minuto.

La ignorancia y estos discursos supuestamente ejemplarizantes y moralistas tuvieron su réplica en obras como "Ignorance=Fear" (Foto 30) de Keith Haring. Sus dibujos simples, firmemente trazados, ondulados y coloristas, apoyados en palabras y signos, mandaban mensajes claros e inequívocos a sobre cómo había que convivir con la enfermedad que mató al propio pintor.

Sus campañas hicieron que poco a poco cambiase la percepción de una enfermedad que generó las primeras obsesiones por el aislamiento del enfermo. Sin duda, la fotografía de Therese Frare de la muerte de David Kirby (Foto 31) que la revista Life publicó en 1990, enseñó al mundo el rostro más trágico del SIDA. La por entonces estudiante logró el segundo premio del World Press Photo. El agónico David aparecía rodeado de su familia mostrando una buscada semejanza con Cristo algo que permitió, dos años después a Oliviero Toscani, convertir la fotografía, con permiso de autora y familia, en icono publicitario de una marca italiana de ropa bajo el título de Pietá.

Se repitieron numerosas campañas que junto al paso del tiempo y el avance de tratamientos hizo que la sociedad terminara viendo la enfermedad de otra forma. Hoy parece olvidada, pero sacude de manera incesante al continente africano.

\section{EL CINE, EL SIDA Y EL ÉBOLA}

- Philadelphia (Jonathan Demne, 1993) 19-21

- Dallas Buyers Club / El club de los desahuciados (Jean Marc Vallée, 2013)

- Outbreak / Epidemia (Wolfgang Peterson, $1995)^{22}$

* Películas comentadas en la Revista de Medicina y Cine

Foto 31. T. Frare (1958-...). Muerte de David Kirby (1990). 
ÉBOLA

La enfermedad por el virus del Ébola o simplemente conocida como ébola, es una enfermedad causada en el ser humano por el virus del mismo nombre. De forma habitual, los síntomas comienzan entre los dos días y las tres semanas después de haber contraído el virus, con fiebre, dolor de garganta, mialgias y cefaleas. Por lo general, siguen náuseas, vómitos y diarrea, junto con fallo hepático y renal. Algunos pacientes presentan complicaciones hemorrágicas. La tasa de mortalidad de la enfermedad es elevada: con una frecuencia de fallecimientos de entre el $50 \%$ y el $90 \%$ de los infectados por el virus. El virus se contagia por contacto con la sangre o los fluidos corporales de animales (generalmente monos o murciélagos frugívoros) y de personas infectadas. No se ha documentado la transmisión aérea ${ }^{23}$.

Nos acompañó en el año 2014 de manera diaria a través de los medios de comunicación en un brote que asoló África Occidental y que llegó hasta España. Desde 1976 hacía acto de presencia en continente africano de manera sistemática y letal. Sin embargo, parece que, como otras tantas cosas que ocurren en este escenario olvidado, no se le prestó demasiada atención hasta ese año en que la enfermedad

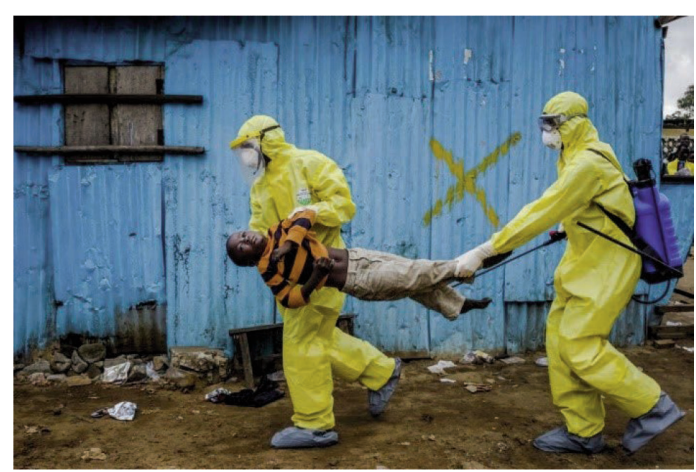

Foto 32. Daniel Berehulak (1975-...) Traslado de James Dorbor (2014). se convirtió en verdadera amenaza para los países desarrollados.

Como ocurriera con el SIDA, campañas como las del fotógrafo Daneil Berehulak desarrollada en Liberia en el año 2014 trajeron a Occidente el verdadero rostro de esta enfermedad aún hoy presente. La fotografía, Traslado de James Dorbor (Foto 32), forma parte de un reportaje que le hizo merecedor del Premio Pulitzer del año 2015.

Hasta aquí este macabro paseo que, a pesar de o gracias a los esfuerzos de los pintores, no oculta el drama de una Humanidad que -como ahoraasiste a la visita de enfermedades o pandemias que junto a los miles de muertos sacuden conciencias y aceptaciones de modos de vida hasta ese momento concebidos como inalterables.

En cualquier caso, en este recorrido faltan dos capítulos que sin duda tienen el indiscutible honor de liderar el ranking en lo que mortandad se refiere. La cara más amarga de estos es su origen: el propio hombre. Las guerras y el hambre tienen a sus espaldas miles y miles de muertos. Son muertos que lo son por una irracional distribución de recursos o por banderas o dioses a los que hay que defender. También a estos dos capítulos los ha acompañado el arte, pero no merecen compartir espacio con estos otros cuya letalidad escapa de la voluntad del hombre que es a la postre la responsable de los fallecidos en conflictos bélicos y en hambrunas. No lo dudemos, las cifras son escandalosamente superiores y los motivos aún más injustificables. 


\section{LOS ÁNGELES DE LA MUERTE: UN RECORRIDO ARTÍSTICO POR LAS GRANDES PANDEMIAS JAVIER LIZASOAIN HERNÁNDEZ; IGNACIO LIZASOAIN HERNÁNDEZ}

\section{REFERENCIAS}

1. Delumeau J. El miedo en Occidente. Madrid: Taurus; 1989.

2. Boccaccio G. Decamerón. Madrid: Cátedra; 2007.

3. Huizinga J. El otoño de la Edad Media. Madrid: Alianza Universidad; 1984.

4. Malthus TH. Ensayo sobre el principio de la población. México: FCE; 1998.

5. Carabias Martín F. La amenaza de las plagas: Pánico en las calles (1950). Rev Med Cine [internet] 2006;2(3): 89-95.

6. Sánchez M. Bioseguridad y armas biológicas: $L a$ amenaza de Andrómeda (1971). Rev Med Cine [internet] 2011.7(1):15-20.

7. Méndez Domínguez N, Rodríguez Castellanos A. Pertinencia del análisis de la película Contagio (2011) en el aprendizaje de la metodología clínica y epidemiológica en medicina. Rev Med Cine [internet] 2016;12(3):147-55

8. Schuenemann VJ, Bos K, DeWitte S, Schmedes S, Jamieson J, Mittnik A, Forrest S, Coombes BK, Wood JW, Earn DJ, White W, Krause J, Poinar HN. Targeted enrichment of ancient pathogens yielding the PPCP1 plasmid of Yersinia pestis from victims of the Black Death. Proc Natl Acad Sci USA. 2011;108(38):E746-52.

9. Ontoso Picón D. La peste (1992). De Albert Camus a Luis Puenzo. Rev Med Cine [internet] 2006;2(1):3-9.

10. Rodrigues LC, Lockwood DNj. Leprosy now: epidemiology, progress, challenges, and research gaps. Lancet Infect Dis. 2011;11(6):464-70.

11. Ghanem KG, Ram S, Rice PA. The Modern Epidemic of Syphilis. N Engl J Med. 2020;382 (9):845-54.

12. Dheda K, Barry CE 3rd, Maartens G. Tuberculosis. Lancet. 2016;387:1211-26.
13. Furin J, Cox H, Pai M. Tuberculosis. Lancet. 2019;393:1642-56.

14. Moore ZS, Seward JF, Lane JM. Smallpox. Lancet. 2006;367:425-35

15. García Sánchez JE, García Sánchez E. La viruela y el cine histórico. Rev Med Cine [internet] 2013;9(3):105-6.

16. D'Ottavio AE. La reina y su médico personal. Evocación ficcional de un histórico escándalo dieciochesco danés. Rev Med Cine [internet] 2013;9(3):120-4.

17. Deeks SG, Overbaugh J, Phillips A, Buchbinder S. HIV infection. Nat Rev Dis Primers. 2015;1: 1-22.

18. Saag MS, Benson CA, Gandhi RT, Hoy JF, Landovitz RJ, Mugavero MJ, et al. Antiretroviral Drugs for Treatment and Prevention of HIV Infection in Adults. 2018 Recommendations of the International Antiviral Society-USA Panel. JAMA 2018;320:379-96.

19. Aijón Oliva J. Philadelphia (1993): las claves de un icono cultural. Rev Med Cine [internet] 2005;1(4):109-14.

20. Pérez Ochoa López L. Philadelphia (1993): Visión del SIDA cuando comenzó a ser tratable. Rev Med Cine [internet] 2006;2(1):21-8.

21. Pintor Holguín E, Herreros Ruiz-Valdepeñas B, Gargantilla Madera P, Gutiérrez Cisneros MJ. 25 años después del estreno de Philadelphia (1993), ¿Qué cosas han cambiado en la infección por VIH?. Rev Med Cine [internet] 2020;16(1):37-42.

22. Camacho Aguilera JF. Epidemia: Un repaso a la fiebre hemorrágica por Ébola. Rev Med Cine [internet] 2013;9(2):70-81.

23. Malvy D, McElroy AK, de Clerck H, Günther S, van Griensven J. Ebola virus disease. Lancet. 2019; 393:936-48. 


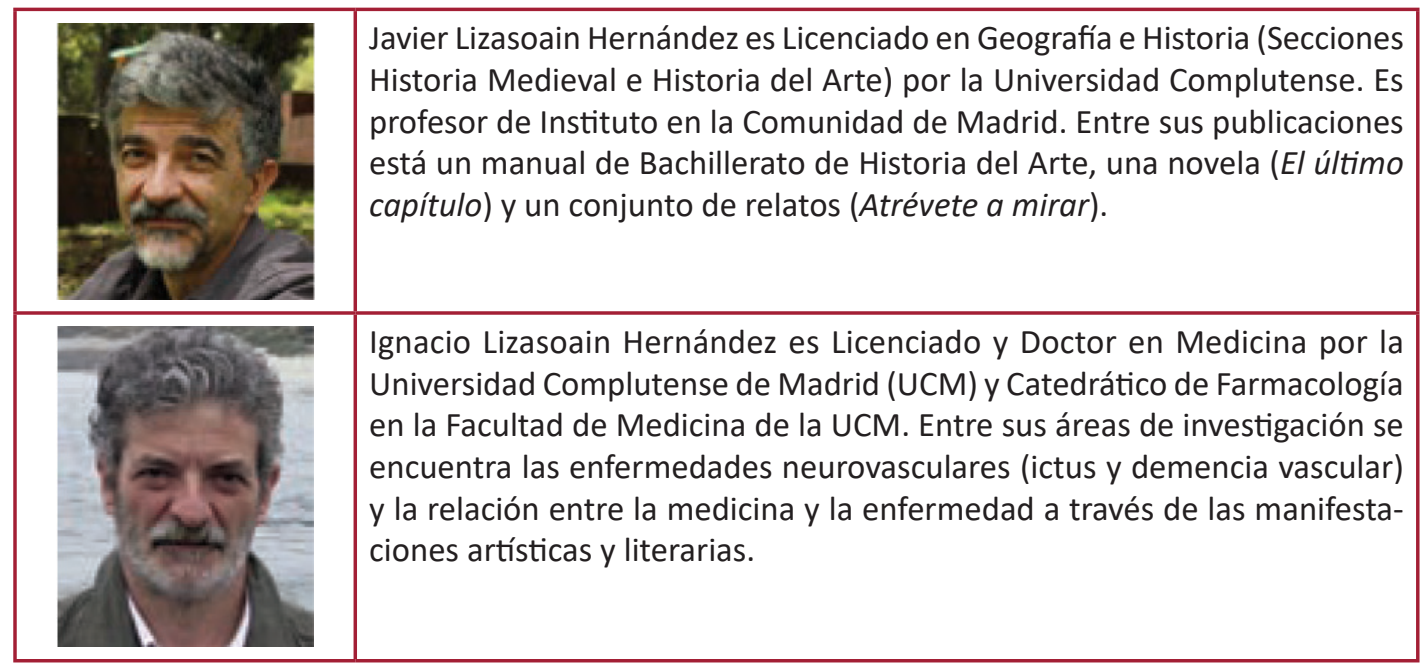

